\title{
CITY-REGIONS: ECONOMIC MOTORS AND POLITICAL ACTORS \\ ON THE GLOBAL STAGE
}

\author{
Allen J. Scott, \\ Department of Public Policy and Department of Geography, \\ UCLA, \\ Los Angeles, \\ CA. 90095 . \\ E-MAIL: ajscott@ucla.edu
}

\begin{abstract}
$\underline{\text { Abstract }}$
A world-wide mosaic of large city-regions seems to be over-riding (though is not effacing entirely) an earlier core-periphery system of spatial organization. The economic dynamics of these city-regions are analyzed with particular emphasis on the ways in which they tend to generate increasing-returns effects and competitive advantages for local producers. The managerial tasks that these city-regions face raise many new issues about local economic development policy and institution building in the interests of social order. These issues lead on to further questions about democracy and citizenship in the new global mosaic of city-regions as well as in the new world system as a whole.
\end{abstract}




\section{$\underline{\text { Introduction }}$}

Contrary to many recent predictions (e.g. O'Brien, 1992), geography is not about to disappear. Even in a globalizing world, geography does not become less important; it becomes, indeed, increasingly important because globalization enhances the possibilities of heightened geographic differentiation and locational specialization. In particular, an extended archipelago or mosaic of large city-regions is currently making its historical and geographical appearance on the global stage, and these peculiar agglomerations are now beginning to function as important spatial foundations of the new world system that has been taking shape since the end of the 1970s (Scott, 1998; Veltz, 1996). The internal and external relations of these city-regions and their complex growth dynamics present a number of extraordinarily perplexing challenges to researchers and policy makers alike as we enter the 21 st century.

There is an extensive literature on "world cities" and "global cities" by analysts such as Hall (1966), Castells (1996), Friedmann and Wolff (1982), Sassen (1991), and Knox (1995), to name only a few. This literature focuses above all on a concept of the cosmopolitan metropolis as a command post for the operations of multinational corporations, as a center of advanced services and information-processing activities, and as a deeply segmented social space marked by extremes of poverty and wealth. I use the same concept as a basic point of departure for the present investigation, but I shall also seek to extend its range of meaning so as to incorporate the notion of the wider metropolitan region as an emerging political-economic unit with increasing autonomy of action at the national and global levels. I shall designate this phenomenon by the term global city-region (Scott et al., 2001). Thus, in practice, and in simple geographic terms, global city-regions are emerging in the form of large metropolitan areas -- or contiguous sets of 
metropolitan areas -- together with surrounding hinterlands of variable extent which may themselves be sites of scattered urban settlements. Moreover, the internal economic and political affairs of these metropolis-hinterland systems are bound up in intricate ways in intensifying and far-flung extra-national relationships. In parallel with these developments, embryonic consolidation of global city-regions into definite territorial-cum-political entities is also occurring as contiguous units of local government (counties, metropolitan areas, municipalities, special administrative areas, etc.) club together to form spatial coalitions in search of effective bases from which to deal with both the threats and the opportunities of globalization. So far from being dissolved away as geographic entities by processes of globalization, city-regions are by and large actually thriving at the present time, and they are, if anything, becoming increasingly central to the conduct and coordination of modern life (cf. Taylor, 2000).

An initial though admittedly inadequate empirical identification of global city-regions today can be made simply by reference to the world map of large metropolitan areas as shown in Figure 1. The figure plainly suggests that large-scale urbanization is of major importance in the contemporary world, and that it is characteristic of both economically-advanced and economically-developing countries. At the same time, large cities all over the globe continue to grow in size. In 1950, there were 83 cities in the world with populations of more than one million (two-thirds of them being located in the economically-advanced countries). In the year 2000 there were 391 such cities (two-thirds of them now being in the economically-developing countries). The United Nations' assessment of future population trends in the world's thirty largest metropolitan areas indicates that this growth can be expected to continue over at least the next few decades (see Table 1). That said, not all large metropolitan areas are equally caught up 
in processes of globalization, and not all global city-regions can be simply identified in terms of existing large metropolitan areas, as we shall see with greater clarity below.

\section{Globalization and the New Regionalism}

In the immediate post-War decades almost all of the major capitalist countries were marked by strong central governments and relatively tightly bordered national economies. These countries constituted a political bloc within the framework of a Pax Americana, itself supported by a rudimentary network of international arrangements (the Bretton Woods system, the World Bank, the IMF, GATT, and so on) through which they sought to regulate their relatively limited - but rapidly expanding -- economic interrelations. Over much of the post-War period, the most prosperous of these countries could be said to constitute a core zone of the world economy, surrounded in its turn by a peripheral zone of Third World nations, with a complex set of interdependencies running between the two, as described by world system theorists like Wallerstein (1979).

Today, after much economic restructuring and technological change, significant transformations of this older order of things have occurred virtually across the world, bringing in their train the outlines of a new social grammar of space, or a new world system (Badie, 1995). One of the outstanding features of this emerging condition is the apparent though still quite inchoate formation of a multilevel hierarchy of economic and political institutions ranging from the global to the local. Four main aspects of this state of affairs call for immediate attention. 1. Huge and ever-increasing amounts of economic activity (input-output chains, migration streams, foreign direct investment by multinational corporations, monetary flows, and so on) 
now occur in the form of cross-border relationships. Such activity is in important ways what I mean by globalization as such, even though it is far indeed from any ultimate point of fulfillment. Further, as globalization in this sense moves forward, it creates numerous conflicts and predicaments that in turn activate a variety of political responses and institution-building efforts. Practical expressions of such efforts include international forums of collective decision-making and action such as the G7/G8 group, the OECD, the World Bank, the IMF, and the World Trade Organization. While these political responses to the pressures of globalization remain limited in scope and severely lacking in real authority, they are liable to expansion and consolidation as world capitalism continues its predictable expansion.

2. In part as a corollary of these same pressures, there has been a proliferation over the last few decades of multi-nation blocs such the EU, NAFTA, MERCOSUR, ASEAN, APEC, CARICOM, and many others. These blocs, too, can be seen as institutional efforts to capture the benefits and control the negative externalities created by the steady spilling over of national capitalisms beyond their traditional political boundaries. They remain in various stages of formation at the present time, with the EU being obviously in the vanguard. Because they involve only small numbers of participants, they are more manageable as political units (i.e. transactions-costs problems are relatively restrained) in comparison with actual or putative global organizations.

3. Sovereign states and national economies remain prominent, indeed dominant elements of the contemporary global landscape, though they are clearly undergoing many sea-changes. On the one hand, individual states no longer enjoy quite the same degree of sovereign political autonomy that they once possessed, and national economies have been subject to massive 
debordering over the last few decades so that it is increasingly difficult, if not impossible, to say precisely where, say, the American economy ends and the German or Japanese economies begin. On the other hand, they find themselves less and less able or willing to safeguard all the regional and sectional interests within their jurisdictions. As a result, and as noted in points 1 and 2 above, some of the regulatory functions that were formerly carried out under the aegis of the central state have been drifting to higher levels of spatial resolution; at the same time, other functions have been drifting downward (Swyngedouw, 1997).

4. Accordingly, and most importantly for the purposes of the present account, there has of late been a resurgence of region-based forms of economic and political organization, with the most overt expression of this tendency being manifest in the formation of large global cityregions. These city-regions form a global mosaic that is now beginning to override or at least complement the system of core-periphery relationships that has characterized much of the macro-geography of capitalist development since its historical beginnings.

Of course, the political map of the contemporary world is vastly more complicated than this simple schema suggests, for it is marked by many inter-scalar and cross-scalar political arrangements as well. Moreover, point 4 calls for much further amplification. The propensity of many types of economic activity - manufacturing and service sectors alike - to gather together in dense regional clusters or agglomerations appears to have been intensifying in recent decades. This renewed quest for collective propinquity on the part of all manner of economic agents can in part be interpreted as a strategic response to heightened (global) economic competition in the context of a turn to post-fordism in modern capitalism. Propinquity is especially important in this context because, as we shall see, it is a source of enhanced competitive advantage for many 
types of firms (Porter, 2001; Scott, 1988; Storper, 1997), and, as a corollary, large regional production complexes are coming increasingly to function as territorial platforms for contesting global markets. At the same time, the diminishing capacity of central governments to deal with all the nuanced policy needs of each of the individual regions contained within their borders means that many regions are now faced with the choice of either passive subjection to external cross-border pressures, or active institution-building, policy-making, and outreach in an effort to turn globalization as far as possible to their advantage. Regions that take the latter course are likely to find themselves also faced with many new tasks of political coordination and representation. These tasks are of special urgency at a time when large city-regions function more and more as poles of attraction for low-wage migrants from all over the world, so that their populations are almost everywhere heavily interspersed with polyglot and often disinherited social groups. As a consequence of this, many city-regions today are being confronted with pressing issues related to political participation and the reconstruction of local political identity and citizenship.

\section{The Economic Order of Global City-Regions}

One of the seeming paradoxes of the field of investigation at hand is that whereas dramatic improvements in technologies of transportation and communication over the last few decades are helping to annihilate the barriers of space by bringing all parts of the world into ever closer contact with one another, dense urban agglomerations continue to increase in size and importance everywhere. These apparently incompatible trends turn out on further scrutiny to be two faces of a mutually reinforcing set of relationships whose geographic logic can in significant 
ways be generally understood in terms of the network arrangements (i.e. relational interdependencies) that constitute the basic structure of organized economic and social life. More accurately, this logic reposes on an intrinsic duality of any economic or social network, namely, (a) its status as an entity with definite spatial extent, signifying that any bilateral or multilateral relationship (or transaction) will always be associated with locationally-dependent impedances or costs, and (b) its status as a social organization marked by forms of bonding and interaction that often result in synergistic outcomes (such as the knowledge spillovers that occur in day-today business dealings between firms, or the information that accumulates and circulates in local labor markets about job opportunities for workers).

The formation of urban superclusters. These remarks lead at once to a number of pertinent insights about the dynamics of geographic systems. These insights are more systematically laid out in the Appendix, but let us consider here, for exemplary purposes, three schematic arrangements of socio-economic relations, each of which expresses in varying degree the duality described above.

1. We begin with a purely fictional case. In world where the time and money costs of spatial interaction are zero, we would expect to observe a state of geographic entropy or randomness. In such a world, all relationships can be actualized instantaneously and freely, no matter where the participants may be located.

2. A more realistic, but still rather simple case can be represented by a production system in which the spatial costs of transacting are uniformly high. Let us also suppose that all economic exchange in this system can be fully described in terms of well-behaved supply and demand mechanisms so that externalities are entirely absent. Here, we would expect 
to observe the kinds of spatial outcomes described by Weberian or Löschian location theory. In particular, firms would tend to locate in ways that minimize their total transport costs relative to basic inputs and markets.

3. In contrast to these two cases, many of the most important kinds of production systems that exist today are characterized by situations of considerable complexity in regard to both transactions costs and externalities. Firms in numerous segments of the modern economy are often tied together in transactional relations that incur extremely high costs (e.g. many kinds of face-to-face exchanges of information). At the same time, the final products of many of the same firms can often be diffused to global markets at relatively low cost, especially where streamlined distribution systems are in place. This is a world, too, in which the interactions between different economic agents frequently give rise to externalities that take the form of increasing-returns effects or competitive advantages that accrue freely, though differentially, to all. The net result will frequently be intense agglomeration of individual firms on the one hand, combined with spatially-extended distribution of final products on the other hand. I shall argue that this state of affairs is highly conducive to the emergence of urban super-clusters, and, more specifically, under appropriate conditions, to the formation of global city-regions.

Note that the leading-edges of the contemporary post-fordist economy are represented by sectors like high-technology production, neo-artisanal manufacturing, cultural-products industries, the media, business and financial services, and so on. These sectors persistently assume the form of intricate networks or complexes of producers (Cooke and Morgan, 1998; Scott, 1998). In sectors like these many groups of producers are usually bound together in 
relations of specialization and complementarity. Where these relations involve frequent, unpredictable, and constantly shifting face-to-face transactions, they are often most effectively carried out under conditions of mutual locational proximity. Accordingly, and on these grounds alone, we can expect to observe some degree of clustering on the part of interrelated producers. By contrast, distribution of the final products of the clusters that form in this manner often incurs relatively low transactions costs per unit of distance, so that overall market reach may be quite extended. These conditions are dramatically exemplified by the motion picture industry of Hollywood where the actual work of production is for the most part carried out by firms linked together within a tightly circumscribed geographic area, whereas final products circulate with ease around the globe (Scott, 2005; Storper and Christopherson, 1987).

Additionally, rich complements of externalities or increasing returns effects typically emanate out of post-fordist industrial networks and these tend to magnify, often many times over, any basic proclivity to agglomeration due purely to the play of transactions costs. These externalities are enormously variable in reality; they range from the fact that the co-presence of many specialized firms in one cluster provides a kind of insurance against critical supply failures due to sudden or unpredictable input needs (an especially important feature in flexible economies where long-run planning of production schedules is extremely problematical), to learning effects set in motion by constant and many-sided interactions between different participants in the local economy. Some of theses externalities, of course, can be appropriated even when the producer(s) and consumer(s) of them lie at a considerable distance from one another. In other cases, and these appear to be of major significance, mutual proximity is again a necessary condition for successful transmission and reception of externality effects. In these 
circumstances, the tendency to agglomeration will be accordingly intensified.

In view of these arguments, we may say that the clustering of economic activities will usually be especially pronounced where three main sets relationships come into mutual alignment with one another. First, where selectively high transactions costs exist in networks of specialized but complementary producers, the latter will have strong inducements to cluster locationally together around their own center of gravity. Second, where spatially dependent transactions costs on final outputs are low, producers will be that much better able to contest distant (and in the limit, global) markets. Moreover, as they do so, the incipient cluster that they form will grow in size, and will also tend to go through further internal differentiation via the division of labor. Third, localized increasing-returns effects embedded in traded and untraded interdependencies among producers will reinforce agglomeration, and will ensure that growth leads on to more growth (cf. Romer, 1986). Above all, where different but functionally overlapping networks of producers come into mutual locational relationship with one another (as illustrated by the cultural-products industries of Los Angeles) massive urban agglomerations are apt to make their appearance. Certainly, in some cases, the agglomerations formed by these processes may encounter constraining factors that impede their continued expansion, especially where external markets for their products are limited in scale. Also, large-scale urban or regional growth often brings in its train a variety of negative externalities that in the absence of remedial action would usually set in motion any number of locationally centrifugal tendencies. What we normally observe in response to this situation, however, is regulatory action on the part of local authorities in order to bring such externalities under at least approximate control. In circumstances where these limits to growth can be eliminated or held in check, agglomerations 
will continue to expand indefinitely in size. The resulting superclusters scattered across the landscape of the contemporary world can provisionally be identified as the core functional units of global city-regions

As large-scale agglomeration occurs at any place, diverse other (contingent and emergent) organizational outcomes enter into play and serve to underpin the dynamics of spatial convergence and growth. Among the more important of these we may count (a) access to the rich physical infrastructures typically supplied out of public funds as cities expand, (b) the formation of dense local labor markets and the concomitant emergence of extended webs of residential services, and (c) the gradual consolidation of conventions and cultures that enhance the capacities of all individuals to perform effectively in the local economic environment (Storper, 1997). Above all, agglomeration has many positive effects on the ability of cities to function as centers of learning, creativity, and innovation, for precisely because cities are constituted as dense transactions-intensive foci of many interdependent activities, they are also places in which new social encounters and experiences endlessly occur, and in which enormous quantities of information are created and circulated in the daily round of business (Scott, 2005). These processes unfold informally in many small, unrecorded events and encounters, but in cumulative terms they function as important foundations of localized innovative energy and successful entrepreneurial effort. They are all the more pervasive in large cities because of the countless combinatorial variations in the kinds of inter-personal encounters that can occur, and out of which there sometimes flow completely unexpected and unpredictable forms of creative action. Large cities, as a result, are invariably important centers of creativity and invention in all sectors of production, (especially perhaps in the neo-artisanal, fashion, and cultural-products industries 
that are typically -- and to an ever greater extent -- found within them in significant concentrations).

The emerging global mosaic of city-regions. Large cities or city-regions, then, have today become a more insistent element of the geographic landscape than at any previous moment in history. Over the last few decades, and throughout the world, numerous suitably positioned urban centers have been transformed into super-clusters whose extent and growth stem from the circumstance that many of the leading sectors of capitalism today are organized as intensely localized networks of producers with powerful endogenous growth mechanisms and with an increasingly global market reach.

A schematic outline of the world map that seems to be coming into being as these processes work themselves out is presented in Figure 2. Here, the more developed parts of the world are represented as a system of polarized regional economies, each consisting of a central metropolitan area and a surrounding hinterland of indefinite spatial extent occupied by ancillary communities, prosperous agricultural zones, smaller tributary centers, and the like. These are the global city-regions identified in the earlier discussion, As shown in the figure, some of these metropolis-hinterland systems may actually fuse together to form yet bigger global city-regions as in the cases of the greater New York, Los Angeles, or Tokyo regions. Each city-region is the site of intricate networks of specialized but complementary forms of economic activity, together with large multi-faceted local labor markets, and each is the locus of powerful agglomeration economies. As such, global city-regions are not only large in size, but also growing constantly larger. These entities, moreover, can be thought of as the regional motors of the new global economy, for they are the principal sites of production, economic growth, and innovation in the 
world today. By the same token, they are caught up in intense interrelationships of trade and exchange.

Equally, there are large expanses of the modern world that lie at the extensive economic margins of capitalism (former colonies, ex-socialist states, areas occupied by traditional cultures resistant to capitalist norms, and so on). Even so, these less developed areas are sometimes punctuated by islands of relative prosperity and opportunity, and some of these are almost certainly aligned along an evolutionary pathway that will lead them eventually to much higher levels of (agglomerated) economic development. In the 1960s and 1970s, places like Hong Kong, Singapore, Seoul, and Mexico City were all positioned along the early stages of this pathway of development. Today, many urban regions in a diversity of low- and middle-income countries (e.g. Bangkok, Guangzhou, and São Paulo) are following on the heels of these pioneers, while parts of Nigeria, India, Indonesia, and possibly Vietnam seem to be poised to follow suit.

In more concrete terms, the schematic map of the world laid out in Figure 2 can be thought of as a structure of nodes and their interconnections involving (a) the leading cityregions of the contemporary world, and (b) a set of subsidiary geographic spaces corresponding to parts of Asia and Latin America and much of Africa. The evolutionary trajectory of this global system is one in which the core mosaic of global city-regions continues to expand by the accession of new nodes originating in the periphery, while the periphery itself recedes constantly if irregularly as developmental impulses flowing through these nodes spread out in geographic space. This model of economic development, combined with export orientation policies, has in a number of instances resulted in spectacular successes, as represented most notably by parts of East and Southeast Asia. 


\section{$\underline{\text { The Political Order of Global City-Regions }}$}

The world system is thus currently in a state of rapid economic flux, leading in turn to many significant adjustments in patterns of political geography. On the one side, the profound changes that have been occurring on the economic front are increasingly giving rise to diverse responses and experiments in regulatory coordination at different geographic levels from the global to the local. On the other side, the new regulatory institutions that are now beginning to assume clearer outline on the world map, simultaneously reinforce the channelling of economic development into spatial structures that run parallel to the quadripartite political hierarchy described earlier. While the political shifts going on at each level in this hierarchy pose many perplexing problems, the level that is represented by the new global mosaic of city-regions is certainly one of the least well understood. Moreover, precisely because the individual regional units at this level constitute the basic motors of a rapidly globalizing production system, much is at stake as they steadily sharpen their political identities and institutional foundations.

We may well ask, at the outset, how these regions are to be defined (in politicalgeographic terms) as territorial units with greater or lesser powers of coordinated action. In many instances, of course, the boundaries of given city-regions will tend to coincide with some preexisting metropolitan area. But how should these boundaries be drawn when several different metropolitan areas lie in close proximity to one another, as, for example, in the case of the northeast seaboard of the United States? And how far out into its hinterland will the political mandate of any city-region range? These questions are in fact moot, at least until we have examined in more detail just what the real political functions of these regions are likely to be, 
though we can - drawing on a traditional marxian approach to the definition of social class provide some methodological guidelines about how they might actually be resolved in any particular case. These guidelines may be summarized in terms of the twin notions of objective

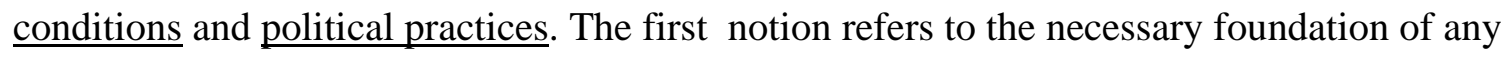
given city-region in a large, dense, polarized (or multipolarized) agglomeration of capital and labor integrated into the world system. The second refers to the active construction of territorial coalitions - whether imposed from above or coming into being from below — in which different geographic entities (say, local government units) join together in the quest for a heightened regional capacity to deal with the administrative and policy problems brought to the fore by the changing world system. In this sense, the final geographic shape of any given global city-region must remain largely indeterminate in a priori terms. That said, we can already perhaps see some of the outlines of things to come in the new regional government systems that have been put into place in a number of different European countries over the last couple of decades, and in the maneuvering (some of which may bear fruit, some of which will certainly lead nowhere) that is currently gathering steam around prospective municipal alliances (many of them involving trans-border agreements) such as San Diego-Tijuana, Cascadia, the TransManche region, Padania, Singapore-Johore-Batam, or Hong Kong-Shenzen.

To an important extent, much of the political change going on in the world's large cityregions today represents a search for structures of governance capable of securing and enhancing their competitive advantages in a rapidly globalizing economic order. Agglomerated production systems, as we have seen, are the arenas of both actual and potential region-wide synergies, but because these synergies so frequently assume the guise of externalities, they will always exist in 
some sub-optimal configuration so long as individual decision-making and action alone prevail in the economic sphere. These synergies have enormous relevance to the destinies of all the firms and workers in the immediate locality, and by the same token, they assume dramatic importance in a world where the continued spatial extension of markets brings each city-region into a position of vastly expanded economic opportunities, but also of greatly heightened economic threats from outside. The economies of large city-regions are thus intrinsically overlain by a field of collective order defined by these synergies, and this constitutes a crucial (though in practice often neglected) domain of social management. No matter what specific institutional form(s) such management may assume (e.g. agencies of local government, privatepublic partnerships, civil associations, and so on), it derives its force and legitimacy from the positive role that coordinating agencies can play in regional economic systems by promoting and shaping critical increasing returns effects that would otherwise fail to materialize or that would be susceptible to severe misallocation. A complete analysis of the complex tasks that agencies like these might play goes well beyond the bounds of the present discussion, but something of their character can be suggested by reference to strategies such as the fostering of agglomerationspecific technological research activities, the provision of high risk capital to small start-up firms, the protection of certain kinds of infant industry, investments in upgrading workers' competencies, the cultivation of collaborative inter-firm relations, the promotion of distant markets for local products, and so on. There is also, of course, a continued urgent need for more traditional types of urban planning to ensure that the negative effects of periodic land use and transportation breakdowns do not cut too deeply into local economic performance and social life. The prospect of a mosaic of global city-regions, each of them characterized by an activist 
collectivity resolutely seeking to reinforce local competitive advantages, however, raises a further series of questions and problems. At the very least, rising levels of concerted regional activism can be expected to lead to specific kinds of destabilization and politicization of interregional relations, both within and across national boundaries. One way in which such predicaments already manifest themselves is in the formation of regional alliances (such as the Four Motors of Europe Program, or the recent attempts to link of the London and Frankfurt stock exchanges), leading to complaints about unfair competition on the part of those excluded. Another resides in the currently prevalent attempts by the representatives of some regions to lure selected assets of other regions into their own geographic orbit, often at heavy social cost. Another can be deciphered in the development races that occur from time to time when different regions push to secure a decisive lead as the dominant center of some budding industry. Still another is clearly evident in the expanding opportunities for multinational corporations to play one region off against another in competitive bidding wars for new direct investments, a phenomenon that is particularly pronounced in contemporary Brazil (Rodríguez-Pose and Tomaney, 1999). In view of the likelihood that stresses and strains of these types will be magnified as the new regionalism takes deeper hold, a need for action at the national, plurinational, and even eventually the global levels of political coordination is foreseeable in order to establish a framework of ground rules for the conduct of inter-regional relations (including aid to failing regions) and to provide appropriate forums for inter-regional problemsolving. The European Committee of the Regions, established under the terms of the Maastricht Treaty, may conceivably represent an early even if still quite fragile expression in the transnational sphere of this dawning imperative. 
As the complex trends and tendencies alluded to in these pages come more resolutely to the surface, a further question arises as to what macro-political or ideological formations will be liable to assert a role in defining the calibrating frameworks for the institution-building and policy-making projects that can now be ever more strongly envisioned at various spatial levels. Giddens (1998) has forcefully argued that two main contending sets of political principles appear now to be moving toward a war of position with one another in relation to recent events on the world stage, certainly in the more economically advanced parts of the globe. One of these is a currently dominant neoliberal view — a view that prescribes minimum government interference in and maximum market organization of economic activity (and that is sometimes but erroneously taken to be a virtually inescapable counterpart of globalization). In light of what I have written above about the urge to collective action in global capitalism and its various appendages, neoliberalism, certainly in the version that crudely advocates laissez-faire as a universal panacea, strikes me as offering a seriously deficient political vision. The other is a renascent social democracy, which, especially in Western Europe, has enjoyed notable electoral success of late. On the economic front, social democracy is prepared to acknowledge and to work with the efficiency-seeking properties of markets where these are consistent with standards of social fairness and long-term economic well-being, but to intervene selectively where they are not. As such, a social democratic politics would seem to be well armed to face up to the tasks of building the social infrastructures and enabling conditions (at every geographic level) that are each day becoming more critical to high levels of economic performance as the new world system comes increasingly into focus. At the city-region level, in particular, these tasks can be centrally identified with the compelling social need to promote those local levels of efficiency, 
productivity and competitiveness that markets alone can never fully secure in these peculiar geographic environments.

There is a further argument in favor of a social democratic approach to the governance of global city-regions, one that is associated with, yet that also goes well beyond, the need for remedial collective action in local economic affairs. Quite simply put, issues of representativeness and distributional impact are always in play in any political community, especially, no doubt, where social management of the local economy is in some sense under way, (cf. Mouffe, 1992). In brief, the question of local democratic practice and how to establish effective forums of popular participation is inescapably joined to the more technocratic issues raised by the challenges of economic governance in global city-regions. This question takes on special urgency in view of the role of large global city-regions as magnets for low-wage migrants -- many of them undocumented -- from all over the world, so that often enough significant segments of their populations are made up of marginalized and politically dispossessed individuals. Moreover, and above and beyond any considerations of equity and social justice, enlargement of the sphere of democratic practice is an important practical means of registering and dealing with many of the social tensions that are especially prone to occur in dense social communities; and this remark in turn is based on the observation that the mobilization of voice in such communities is typically an important first step in the constructive treatment of their internal dysfunctionalities. Large city-regions, with their rising levels of social distress as a result of globalization are confronted with a series of particularly urgent political challenges in this regard, not only because their internal conviviality is in jeopardy, but also because any failure to act is likely, too, to undermine the effectiveness of more purely economic 
strategies.

From all of this, it follows that some reconsideration of the everyday notion of citizenship is itself long overdue. An alternative definition of citizenship, one that is more fully in harmony with the unfolding new world system, would presumably assign basic political entitlements and obligations to individuals not so much as an absolute birthright, but as some function of their changing involvements and practical allegiances in given geographic contexts. In fact, traditional conceptions of the citizen and citizenship are vigorously in question at every geographic level of the world system - for we are all of us rapidly coming to be, at one and the same time, participants in local, national, plurinational, and global communities — but nowhere as immediately or urgently as in the large global city-regions of the new world system (cf. Holston, 2001; Keating, 2001). Even though only a few tentative and pioneering instances of pertinent reforms in such regions are as yet in evidence (as in certain countries of the European Union), increasing numbers of experiments in local political enfranchisement will no doubt come to be initiated in the near future as city-regions start to deal seriously with the new economic and political realities that they face. In a world where mobility is continually increasing, it may not be entirely beyond the bounds of the conceivable that individuals will one day freely acquire title of citizenship in large city-regions many times over in conjunction with their movements from place to place throughout their lifetimes.

\section{Coda}

Globalization has potentially both a dark, regressive side and a more hopeful, progressive side. Insistent globalization under the aegis of a triumphant neoliberalism would no doubt 
constitute something close to a worst-case scenario, leading to greatly increased social inequalities and tensions within city-regions and exacerbating the discrepancies in growth rates and developmental potentials between different parts of the world. If the analysis presented here turns out to be in principle broadly correct, however, then an alternative and attainable form of globalization can be envisaged, one that serves equally the goals of rising economic prosperity and progressive political reform. In the previous pages, I have tried to sketch out some of the elements of a plausible alternative vision. Globalization, indeed, is the potential bearer of many significant social benefits. At this stage in history, its onward course is still quite open-ended, and it will certainly be subject in the future to many different kinds of political contestation, some of which will mold it in decisive ways. In particular, and as I have tried to indicate, globalization raises important new questions about economic governance or regulation at all spatial levels, and some form of social market politics seems to offer a viable, fair, and persuasive way of facing up to these questions. Global city-regions are likely to find themselves in the vanguard of experiments in the search for this brave new world.

\section{$\underline{\text { References }}$}

B. Badie (1995) La Fin des Territoires: Essai sur le Désordre International et sur l'Utilité Sociale du Respect, Paris: Fayard.

M. Castells (1996) The Rise of the Network Society, Oxford: Blackwell.

P. N. Cooke and K. Morgan (1998) The Associational Economy: Firms, Regions, and Innovation, Oxford: Oxford University Press.

J. Friedmann and G. Wolff (1982) "World city formation: an agenda for research and action," International Journal of Urban and Regional Research, 6, 309 - 344. 
A. Giddens (1998) The Third Way: The Renewal of Social Democracy, Cambridge: Polity.

P. G. Hall (1966) The World Cities, London: Weidenfeld and Nicolson.

P. Hirst and G. Thompson (1996) Globalization in Question, Cambridge: Polity Press.

J. Holston (2001) "Urban citizenship and globalization,” in A. J. Scott (ed.) Global City-Regions, Oxford: Oxford University Press.

M. Keating (2001) "Governing cities and regions: territorial reconstruction in a global age," pp. 371-390 in A. J. Scott (ed.) Global City-Regions, Oxford: Oxford University Press.

P. L. Knox (1995) "World cities and the organization of global space," pp. 232 - 247 in R. J. Johnston, P. J. Taylor, and M. J. Watts (eds.) Geographies of Global Change: Remapping the World in the Late Twentieth Century, Oxford: Blackwell.

P. Krugman (1996) Pop Internationalism, Cambridge, MA.: The MIT Press.

C. Mouffe (1992) "Democratic citizenship and political community," pp. 225 - 239 in C. Mouffe (ed.) Dimensions of Radical Democracy, London: Verso.

R. O’Brien (1992) Global Financial Integration: the End of Geography, London: Pinter.

M. Porter (2001) "Regions and the new economics of competition," in A. J. Scott (ed.) Global City-Regions, Oxford: Oxford University Press.

A. Rodríguez-Pose and J. Tomaney (1999) "Industrial crisis in the centre of the periphery: stabilisation, economic restructuring and policy responses in the São Paulo metropolitan region," Urban Studies, 36, $479-498$.

P. M. Romer (1986) "Increasing returns and long-run growth,” Journal of Political Economy, 94, $1002-1037$.

S. Sassen (1991) The Global City: New York, London, Tokyo, Princeton: Princeton University Press.

A. J. Scott (1988) New Industrial Spaces: Flexible Production Organization and Regional Development in North America and Western Europe, London: Pion.

A. J. Scott (1998) Regions and the World Economy: The Coming Shape of Global Production, Competition, and Political Order, Oxford: Oxford University Press.

A. J. Scott (2005) On Hollywood: the Place, the Industry, Princeton: Princeton University Press. 
A. J. Scott (2005) "Entrepreneurship, Innovation, and Industrial Development: Geography and the Creative Field Revisited," Small Business Economics, (forthcoming).

A. J. Scott, J. Agnew, E.W. Soja, and M. Storper. (2001). "Global city-regions”, pp 11-30 in A. J. Scott (Ed.), Global City-Regions: Trends, Theory, Policy. Oxford: Oxford University Press.

M. Storper (1997) The Regional World: Territorial Development in a Global Economy, New York: Guilford Press.

M. Storper and S. Christopherson (1987) "Flexible specialization and regional industrial agglomerations: the case of the US motion-picture industry," Annals of the Association of American Geographers, 77, $260-282$.

E. Swyngedouw (1997) "Neither global nor local: glocalization and the politics of scale," pp. 137 - 166 in K. R. Cox (ed.) Spaces of Globalization: Reasserting the Power of the Local, New York: The Guilford Press.

P. J. Taylor (2000) "World cities and territorial states under conditions of contemporary globalization," Political Geography, 19, 5 - 32.

United Nations (2002) World Urbanization Prospects: The 2001 Revision, New York: UN.

P. Veltz (1996) Mondialisation, Villes et Territoires: L'Economie d'Archipel, Paris: Presses Universitaires de France.

I. Wallerstein (1979) The Capitalist World Economy, Cambridge: Cambridge University Press. 
APPENDIX: Locational outcomes as a function of spatial linkage costs and localized increasing returns effects.

The following diagram shows six main sets of locational outcomes, identified in relation to the horizontal and vertical axes. In the horizontal dimension spatial linkage or transactions costs (per unit of transactional activity) are changing from uniformly low, through mixed low and high, to uniformly high values. The horizontal axis refers to states of the world where localized increasing returns effects either high or low.

\begin{tabular}{|c|c|c|c|c|}
\hline & & \multicolumn{3}{|c|}{ Spatially-determinate linkage costs } \\
\hline & & Low & $\begin{array}{l}\text { Mixed low } \\
\text { and high }\end{array}$ & High \\
\hline \multirow{2}{*}{$\begin{array}{l}\text { Localized } \\
\text { increasing } \\
\text { - } \\
\text { returns } \\
\text { effects }\end{array}$} & Low & $\begin{array}{l}\text { A } \\
\text { Spatial } \\
\text { entropy }\end{array}$ & $\begin{array}{l}\text { B } \\
\text { Intermediate } \\
\text { states between } \\
\text { A and C }\end{array}$ & $\begin{array}{l}\text { C } \\
\text { Weberian- } \\
\text { Löschian } \\
\text { landscapes }\end{array}$ \\
\hline & High & $\begin{array}{l}\text { D } \\
\text { Small } \\
\text { interconnecte } \\
\text { d clusters }\end{array}$ & $\begin{array}{l}\text { E } \\
\text { Superclusters }\end{array}$ & $\begin{array}{l}\mathrm{F} \\
\text { Small } \\
\text { disconnected } \\
\text { clusters }\end{array}$ \\
\hline
\end{tabular}

Five brief remarks on the contents of the diagram need to be made. In all cases it is assumed that there is some pre-existing — physically and historically-given — geographic distribution of basic resources and fixed capital assets. Without this assumption, the analytically derived locational outcomes would in most cases collapse into a single simple result, namely, the concentration of all economic activity into a single agglomeration.

1. Spatial entropy (randomness) of all locational activities occurs when spatial linkage costs are zero and when localized increasing returns effects are zero (panel A)

2. With high spatial linkage costs but no increasing returns effects, the space-economy will be describable in terms of Weberian-Löschian landscapes, i.e. simple transport-cost minimizing geographic patterns (panel C)

3. Where spatial linkage costs are on the whole high and increasing returns effects are also 
high, small disconnected agglomerations will tend be to observable (as in the case, for example, of proto-industrial craft communities). The presence of increasing returns effects will encourage the formation of agglomerations, but the generally high linkage costs will make it difficult for any given agglomeration to grow because of limited access to external markets (panel F).

4. If spatial linkage costs are on the whole low while increasing returns effects are high, small interconnected agglomerations will occur. Producers will agglomerate because of the joint availability of increasing returns effects but only in relatively small numbers because the low linkage costs make it possible for many kinds of transactions (whether synergistic or not) to proceed successfully over long distances (panel D).

5. The most important case for our purposes here is represented by a situation where the linkage system is composed of a mix of high-cost and low-cost spatial interactions, and where increasing returns effects are persistently high. The net outcome in this instance will tend to be the emergence of superclusters. The latter will be especially well developed where there is (a) a proliferation of high-cost linkages reinforcing agglomeration of interrelated producers, combined with (b) the existence of low-cost linkages on final products enabling producers to command distant (and in the limit global) markets (panel E). 


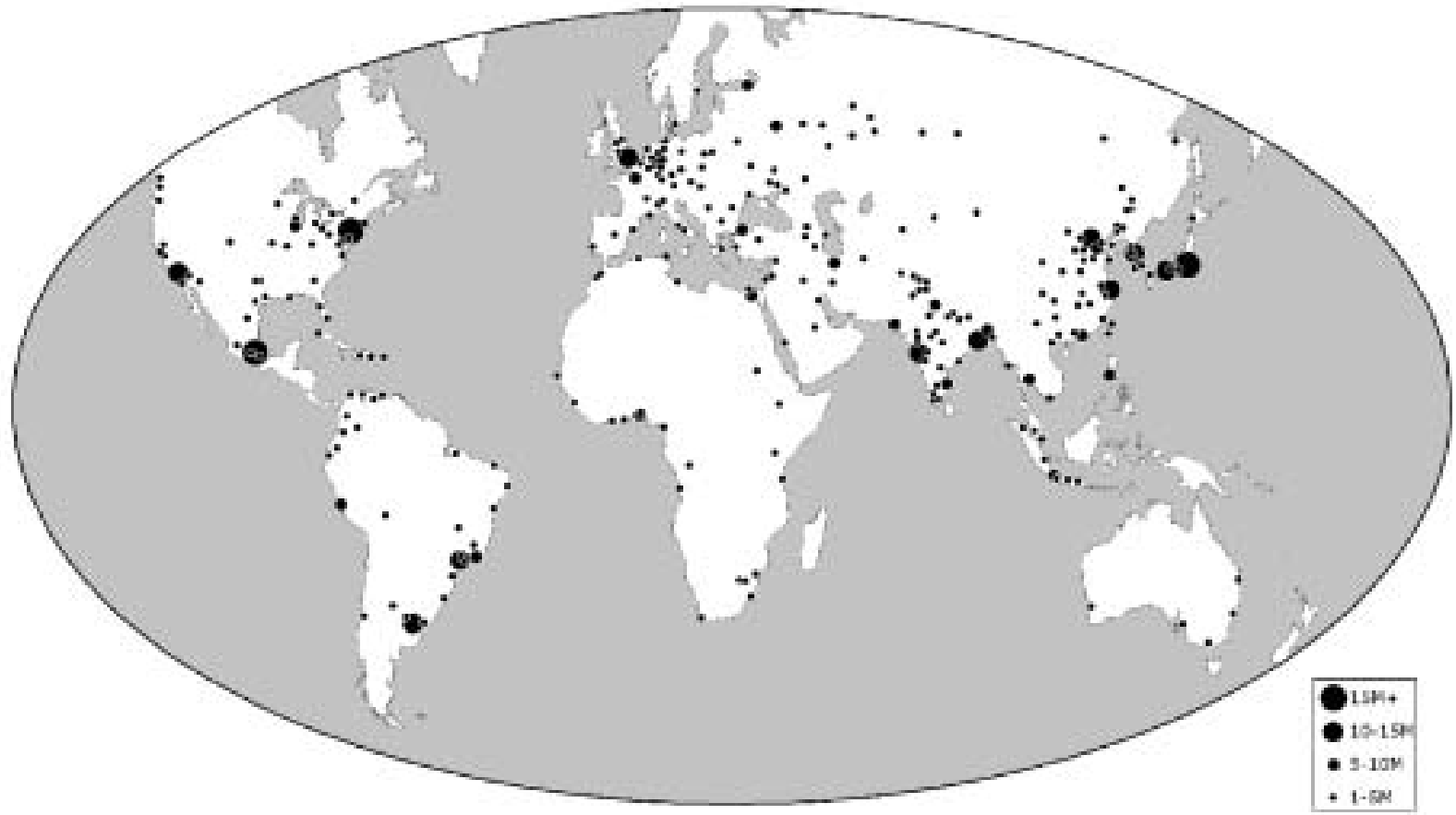

Figure 1. World distribution of metropolitan areas with populations greater than one million. Source of data: United Nations, (1995). 


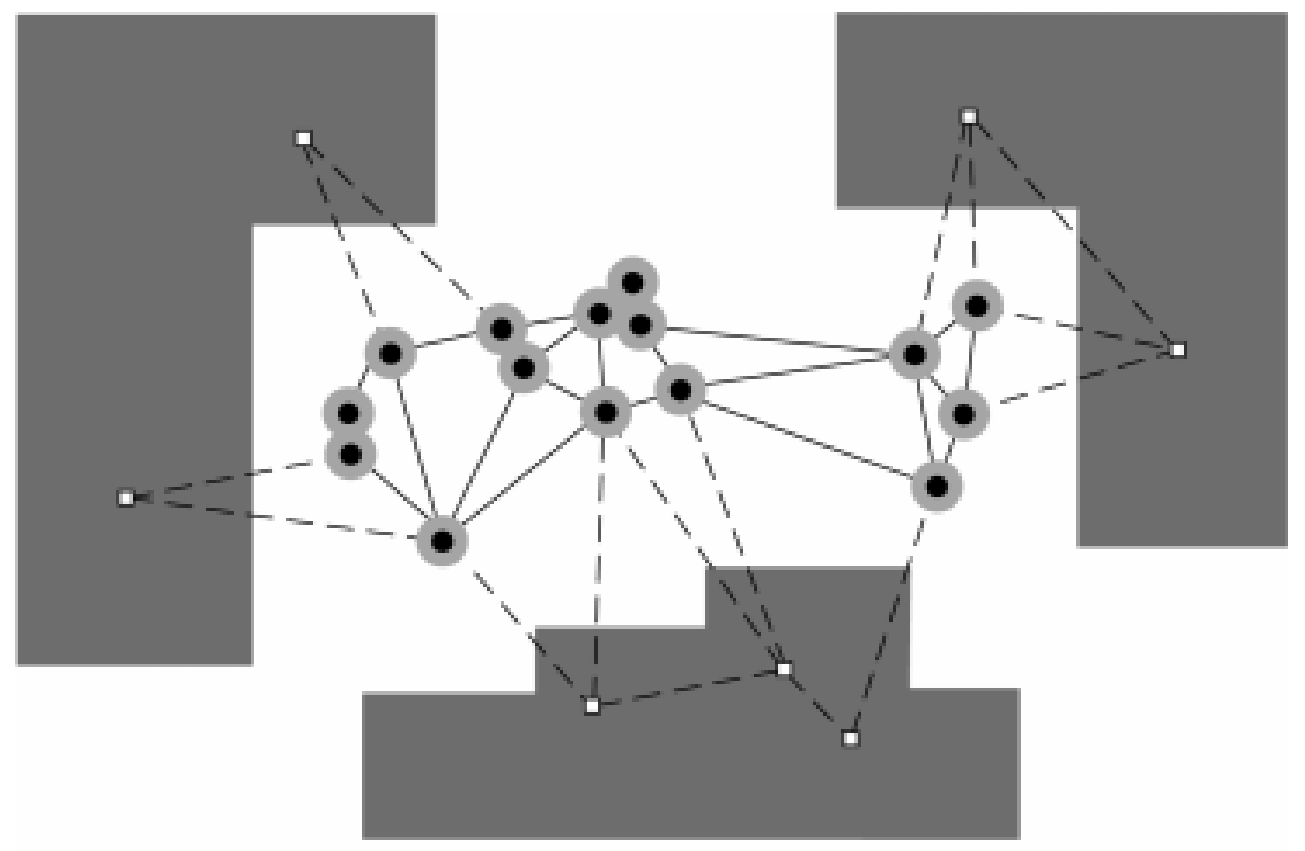

\section{Global city-region}

口 Island of relative prosperity and economic opportunity

Extensive economic frontiers of global capitalism

Figure 2. A schematic representation of the contemporary geography of global capitalism. 
Table 1. The world's thirty largest urban areas ranked by population in the year 2000 .

\begin{tabular}{|lccccc|}
\hline & \multicolumn{5}{c}{ Population (millions) } \\
\\
\multicolumn{1}{|c}{ Urban Area } & 1950 & 1970 & 1990 & 2000 & 2015 \\
& & & & & (estimate) \\
1 Tokyo, Japan & 6.9 & 16.5 & 25.1 & 26.4 & 27.2 \\
2 Mexico City, Mexico & 3.1 & 9.1 & 15.1 & 18.1 & 20.4 \\
3 São Paulo, Brazil & 2.4 & 8.1 & 14.8 & 18.0 & 21.2 \\
4 New York, USA & 12.3 & 16.2 & 16.1 & 16.7 & 17.9 \\
5 Mumbai, India & 2.9 & 5.8 & 12.2 & 16.1 & 22.8 \\
6 Calcutta, India & 4.4 & 6.9 & 10.7 & 13.1 & 16.7 \\
7 Los Angeles, USA & 4.0 & 8.4 & 11.5 & 13.1 & 14.5 \\
8 Shanghai, China & 5.3 & 11.2 & 13.5 & 12.9 & 13.6 \\
9 Dhaka, Bangladesh & 0.4 & 1.5 & 5.9 & 12.5 & 22.8 \\
10 Delhi, India & 1.4 & 3.5 & 8.2 & 12.4 & 20.9 \\
11 Karachi, Pakistan & 1.0 & 3.1 & 8.0 & 12.1 & 16.2 \\
12 Buenos Aires, Argentina & 5.0 & 8.4 & 10.6 & 12.0 & 13.2 \\
13 Jakarta, Indonesia & 1.5 & 3.9 & 9.3 & 11.0 & 17.2 \\
14 Osaka, Japan & 4.1 & 9.4 & 10.5 & 11.0 & 11.0 \\
15 Beijing, China & 3.9 & 8.1 & 10.9 & 10.8 & 11.7 \\
16 Rio de Janeiro, Brazil & 2.9 & 7.0 & 9.5 & 10.7 & 11.5 \\
17 Metro Manila, Philippines & 1.5 & 3.5 & 8.0 & 10.0 & 12.6 \\
18 Seoul, South Korea & 1.0 & 5.3 & 10.6 & 9.9 & 9.9 \\
19 Paris, France & 5.4 & 8.5 & 9.3 & 9.6 & 9.9 \\
20 Cairo, Egypt & 2.4 & 5.3 & 8.6 & 9.4 & 11.5 \\
21 Tianjin, China & 2.4 & 5.2 & 9.3 & 9.2 & 10.3 \\
22 Istanbul, Turkey & 1.1 & 1.4 & 6.5 & 8.9 & 11.3 \\
23 Lagos, Nigeria & 0.3 & 1.4 & 7.7 & 8.6 & 16.0 \\
24 Moscow, Russia & 5.4 & 7.1 & 9.0 & 8.3 & n.a. \\
25 London, U.K. & 8.7 & 8.6 & 7.3 & 7.6 & n.a. \\
26 Lima, Peru & 1.0 & 2.9 & 6.5 & 7.4 & 9.4 \\
27 Bangkok, Thailand & 1.4. & 3.1 & 5.9 & 7.3 & 9.8 \\
28 Chicago, USA & 4.9 & 6.7 & 6.8 & 7.0 & n.a. \\
29 Teheran, Iran & 1.9 & 3.3 & 6.4 & 7.0 & 8.2 \\
30 Hong Kong & 1.6 & 3.5 & 5.7 & 6.9 & n.a. \\
\hline
\end{tabular}

Source: United Nations (2002)

n.a. = data not available 